\title{
Growth variability in the splitnose rockfish Sebastes diploproa of the northeast Pacific Ocean: pattern revisited
}

\author{
Vladlena V. Gertseva ${ }^{1, *}$, Jason M. Cope ${ }^{2}$, Sean E. Matson ${ }^{3}$ \\ ${ }^{1}$ Fishery Resource Analysis and Monitoring Division, Northwest Fisheries Science Center, NOAA Fisheries, \\ 2032 South East OSU Drive, Newport, Oregon 97365, USA \\ ${ }^{2}$ Fishery Resource Analysis and Monitoring Division, Northwest Fisheries Science Center, NOAA Fisheries, \\ 2725 Montlake Boulevard East, Seattle, Washington 98112, USA \\ ${ }^{3}$ Sustainable Fisheries Division, Northwest Regional Office, NOAA Fisheries, 7600 Sandpoint Way NE, Seattle, \\ Washington 98115, USA
}

\begin{abstract}
Understanding patterns of somatic growth within populations greatly contributes to fisheries stock assessment. Splitnose rockfish Sebastes diploproa was reported as having a striking pattern of latitudinal growth variability from studies conducted in the $1980 \mathrm{~s}$. We investigated variation in growth parameters of splitnose rockfish by latitude using recent data from the NOAA Fisheries Groundfish Survey (2003-2008), current ageing techniques, and advanced modeling and statistical methods to provide an updated understanding of growth along this species' latitudinal range. Sex-specific age data were fit to a von Bertalanffy growth function incorporating ageing error, and growth parameters were estimated for 5 areas along the U.S. west coast, specified based on biogeographic boundaries. Resampled values of each growth parameter were then fit to linear models, and Akaike's information criterion (AIC) was used to evaluate hypotheses for growth parameter relationship with latitude. We found that splitnose rockfish exhibited a cline in asymptotic length $\left(L_{\infty}\right)$, with $L_{\infty}$ increasing with rising latitude. We also found that although the growth coefficient $(k)$ was smallest in the most southern area, there was no apparent cline along the coast; a northward cline in $k$ has previously been reported in the literature. We propose that differences in fishing intensity could be responsible for the cline in $L_{\infty}$ as higher fishing pressure in the south could skew the size distribution of the population in that region and reduce southern $L_{\infty}$ estimates. We also attribute slower growth in the southern area to oceanographic characteristics and low productivity of the area south of Point Conception.
\end{abstract}

KEY WORDS: Splitnose rockfish • Northeast Pacific Ocean · von Bertalanffy growth parameter • Latitudinal variability

Resale or republication not permitted without written consent of the publisher

\section{INTRODUCTION}

Knowledge of life history characteristics, specifically patterns of somatic growth within populations, contributes greatly to fisheries stock assessment. Differences in life history parameters have long been used to identify different fishery stocks (Ihssen et al. 1981, Begg \& Waldman 1999, Begg 2005), while estimates of growth parameters drive age-structured population models (Quinn \& Desiro 1999, Haddon 2001, Hilborn \& Walters 2001) and often help estimate other related life history characteristics that are difficult to determine, such as natural mortality (Hoenig 1983, Charnov 1993). Understanding variability in life history characteristics in space and time further helps to determine the proper assessment model structure as well as address uncertainty in assessment results. 
The splitnose rockfish Sebastes diploproa is one of more than 60 rockfish species that inhabit the northeast Pacific Ocean, between the Gulf of Alaska and central Baja California (Love et al. 2002, Gertseva et al. 2009). It can live up to $100 \mathrm{yr}$, and a maximum size of $46 \mathrm{~cm}$ has been reported (Boehlert 1980, Love et al. 2002). The species occurs at depths between 91 and $795 \mathrm{~m}$, with a notable ontogenetic shift to deeper waters as they age (Boehlert 1977, 1978). Adults are most abundant between British Columbia and southern California at depths from 215 to $350 \mathrm{~m}$, where they are primarily found on low-relief mud fields, often near isolated rock, cobble, or shell debris (Alverson et al. 1964, Gunderson \& Sample 1980, Love et al. 2002, Gertseva et al. 2009). Individual fish are commonly found resting on the seafloor, although they occasionally form schools that move more than $100 \mathrm{~m}$ up in the water column (Rogers 1994, Love et al. 2002). Adult splitnose rockfish movements are not well understood, but studies suggest that most rockfish species do not travel large distances (Love et al. 2002).

Splitnose rockfish co-occur with many slope rockfishes, including Pacific ocean perch Sebastes alutus, darkblotched rockfish Sebastes crameri, yellowmouth rockfish Sebastes reedi, sharpchin rockfish Sebastes zacentrus, and shortspine thornyhead Sebastolobus alascanus, along with other groundfish species (Rogers \& Pikitch 1992, Williams \& Ralston 2002). Splitnose are not targeted by commercial fisheries, but have historically been taken as bycatch in the Pacific ocean perch fishery (Boehlert 1980, Tagart \& Kimura 1982, Rogers 1994, Gertseva et al. 2009) and fisheries for mixed slope rockfish or other deepwater targets (Gertseva et al. 2009). Because of their small size, splitnose rockfish have a limited market and are often discarded (Rogers 1994, Love et al. 2002), with $100 \%$ discard mortality due to barotrauma and other causes. Although splitnose rockfish is not a targeted species, there has been concern that it could be overharvested (Rogers 1994), because several species that co-occur with it-specifically Pacific ocean perch and darkblotched rockfishwere assessed and declared overfished (Hamel 2005, Rogers 2005). To address this concern, a stock assessment of the splitnose rockfish was conducted in 2009 (Gertseva et al. 2009). In order to develop the assessment model, a variety of fishery-dependent and fishery-independent data was analyzed to reconstruct historical catches, compute survey abundance indices, describe selectivity and retention curves, and estimate key life history parameters.

Many aspects of splitnose rockfish life history have been studied. It was found that splitnose rockfish exhibit sexual dimorphism in growth: males grow to their maximum lengths faster than females, while females reach larger sizes than males (Boehlert 1980,
Love et al. 2002). Boehlert (1980) described the strong gradient of body size with depth for splitnose rockfish, with smaller fish in shallow waters, suggesting ontogenetic movements to deeper waters with increasing size and age (Boehlert 1980). Boehlert \& Kappenman (1980) reported increases in size and size-at-age of splitnose rockfish with increasing latitude and suggested more rapid growth of fish in the northern end of their range. They provided several explanations for their results including the possibility that 2 stocks of splitnose rockfish might exist in the northeast Pacific Ocean, with a suggested breakpoint at Cape Mendocino (Fig. 1). Rogers (1994), however, did not find any distinct differences in size-at-age between north and south, but there were not enough data and life history information to address the hypothesis of separate stocks.

The age of a fish is usually determined from calcified hard parts, often otoliths, wherein many teleost fish deposit growth increments as annuli (Bennett et al.

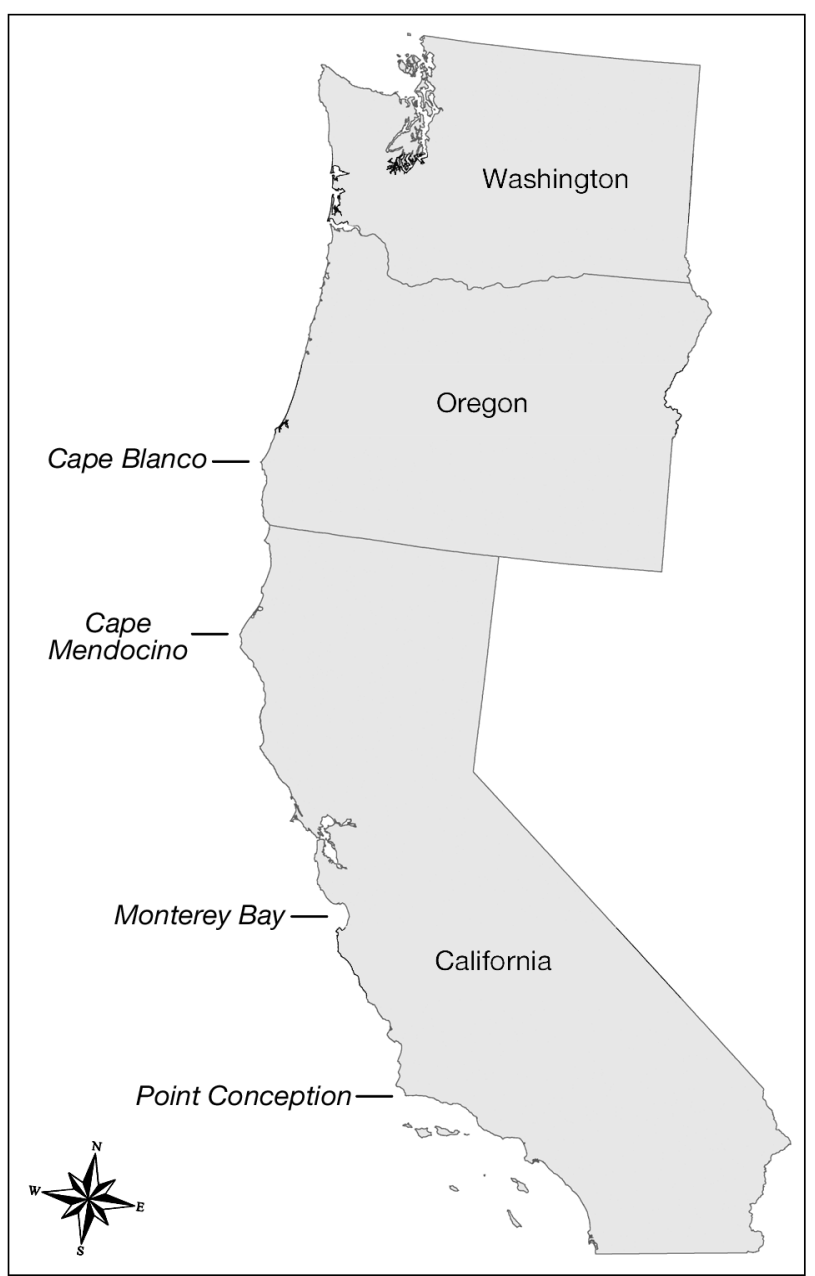

Fig. 1. Studied area with biogeographic breakpoints at Cape Blanco, Cape Mendocino, Monterey Bay, and Point Conception used to define areas for the analysis 
1982, Boehlert 1985, Lai et al. 1995). Two methods have been used to determine fish age from otoliths: one is based on counting annuli on the surface of whole otoliths, and the other entails sectioning them and counting internal bands (Lai et al. 1995, Love et al. 2002). The former method was common prior to the late 1980s until research demonstrated significant differences among ages estimated by these 2 methods, especially for older fish. This is primarily because otoliths thicken with age, which makes it difficult to distinguish annuli on the surface (Boehlert 1985). For example, Bennett et al. (1982) compared ages estimated from splitnose rockfish otolith surfaces versus sections, and found that although the 2 estimates agree through the first $22 \mathrm{yr}$, beyond that they diverge significantly, with otolith sections producing higher age estimates. Bennett et al. (1982) also found that sectioned otolith age estimates exceeded whole otolith surface estimates by approximately $50 \mathrm{yr}$, and age verification using radiometric analysis, based on the measurements of ${ }^{210} \mathrm{~Pb} /{ }^{226} \mathrm{Ra}$ radioactive disequilibrium, supported estimates generated from the sectioning method.

Most of the previous studies of splitnose rockfish growth were based on age data estimated from whole otolith surfaces rather than sections (Boehlert 1980, Boehlert \& Kappenman 1980). Also, previous studies of growth did not take into account measurement error in reading otoliths. At the same time, it has been shown that there is significant variability in age estimates generated from the same otoliths among readers and among laboratories (Boehlert \& Yoklavich 1984). Therefore, in the 2009 splitnose rockfish stock assessment, there was a strong need to revisit the results of previous studies regarding splitnose growth by using the most recent data, the most current ageing techniques, and advanced modeling methods to fit growth curves.

Over the last several years, a significant amount of new data on splitnose rockfish has been collected. Since 2003 the NOAA Fisheries Groundfish Survey, conducted by the Northwest Fisheries Science Center (NWFSC), on the continental shelf and slope of the northeast Pacific Ocean has collected information on abundance, sex, size, and age compositions of splitnose rockfish. For the present study we used these new data to estimate growth parameters while taking into account ageing error for both sexes separately in each of 5 areas along the U.S. west coast, specified based on biogeographic barriers. We also formulated and explored specific hypotheses as for how these parameters may vary over the latitudinal range of the species, including no trend in parameters, a break at Cape Blanco, Cape Mendocino, Monterey Bay, or Point Conception, as well as a cline in parameters along the coast. Finally, we provided possible explanations as to what mechanisms might be responsible for the observed growth patterns in splitnose rockfish along the west coast of the United States.

\section{MATERIALS AND METHODS}

Size and age data used in the present study were collected during the NOAA Fisheries Groundfish Survey off the west coast of the United States. The survey has been conducted annually since 2003 and has consistently covered a latitudinal range between $32^{\circ} 34^{\prime}$ and $48^{\circ} 22^{\prime} \mathrm{N}$ latitudes and depths of 55 to $1280 \mathrm{~m}$ (30 to $700 \mathrm{fm}$ ). The survey is conducted from late May to early October, and is divided into 2 passes, with 2 vessels operating during each pass. The survey is based on a random-grid design, and 4 vessels per year are assigned to an approximately equal number of randomly selected grid cells, so that the survey is able to incorporate vessel-to-vessel differences in catchability. The survey methods are described in detail in Keller et al. (2007).

Biological samples (e.g. fish lengths and otoliths), regularly collected during the survey, comprise the data used in the present study. Fish lengths were measured as fork length to the nearest centimeter. Splitnose rockfish otoliths were collected and then read by agers from the Ageing Laboratory in the NWFSC Newport Research Station. Sectioned otoliths were used for age determination. To enhance readability of the growth increments, a break-and-burn method was used, when otoliths are broken in half and the exposed interior surfaces are charred with a flame (Lai et al. 1995, Love et al. 2002). Age structures collected by the survey were first read by a single reader (Reader A). Then, a subsample of 468 otoliths was read again by a second reader (Reader B) to evaluate uncertainty in reading otoliths (relative bias and imprecision) (Beamish \& Fournier 1981, Chang 1982, Campana 2001).

The surveyed area was divided into 5 regions based on potential biogeographic barriers that included Cape Blanco, Cape Mendocino, Monterey Bay, and Point Conception (Fig. 1). Point Conception has long been considered a major oceanographic transition zone (Parrish et al. 1981, Burton 1998), while recent studies have suggested that significant barriers to species distributions may be found near Monterey Bay (Sivasundar \& Palumbi 2010), Cape Mendocino (Cope 2004, Waples et al. 2008, Hyde \& Vetter 2009), and Cape Blanco (Broitman et al. 2008, Johansson et al. 2008).

The von Bertalanffy growth function (von Bertalanffy 1938) was used to model the relationship between length and age of the splitnose rockfish. This is the most widely applied somatic growth model in 
fisheries, and has been shown to be appropriate for a number of rockfish species (Quinn \& Desiro 1999, Haddon 2001, Hilborn \& Walters 2001, Love et al. 2002). The equation for the von Bertalanffy relationship between size, $L$, and age, $t$, is given below:

$$
L(t)=L_{\infty}\left(1-\mathrm{e}^{-k\left(t-t_{0}\right)}\right)
$$

where $L_{\infty}$ is the asymptotic length, $k$ is the growth coefficient, commonly used to describe growth rate (the greater the value of $k$, the faster the growth), and $t_{0}$ is the age at which size is estimated to be 0 (i.e the $x$ intercept).

The von Bertalanffy growth function was fitted using a random effects framework, described by Cope \& Punt (2007), a method that allows explicit incorporation of ageing error from multiple age reads when estimating von Bertalanffy growth parameters. Growth models were developed for each of the 5 biogeographic areas for females and males separately to account for sexual dimorphism in growth, and mean and asymptotic standard deviations for each growth parameter by gender and biogeographic area were obtained.

We then formulated and explored 6 specific hypotheses as to the relationship of the von Bertalanffy growth parameters $L_{\infty}$ and $k$ among biogeographic areas. These hypotheses included: (1) no trend in parameters among areas (1 area hypothesis), (2) parameter values are significantly different in each of the 5 biogeographic regions and a latitudinal cline in parameters is observed (5 areas hypothesis), parameter estimates are different north and south of (3) Cape Blanco, (4) Cape Mendocino, (5) Monterey Bay, and (6) Point Conception.

To evaluate competing hypotheses, we employed an information-theoretic approach (Burnham \& Anderson 2002), which is becoming increasingly common in ecology (Hilborn \& Mangel 1997, Hobbs \& Hilborn 2006). This approach provides several important advantages over traditional methods by allowing the evaluation of multiple hypotheses based on relative strength of evidence in data and taking into account uncertainty in the parameters. In order to test for differences in $L_{\infty}$ and $k$ across areas, a bivariate normal distribution was used to generate $L_{\infty}$ and $k$ values based on the number of individuals and correlations between parameters for each gender-area combination. Linear regressions were used to fit the area and gender specific simulated parameter data to each of the formulated hypotheses. Akaike's information criterion (AIC) was then used to select which model fits the data best (Burnham \& Anderson 2002). All analysis was conducted using $\mathrm{R}$ ( $\mathrm{R}$ Development Core Team 2010).

\section{RESULTS}

A map of splitnose rockfish catch density during the NOAA Fisheries Groundfish Survey (2003-2008) is shown in Fig. 2. The map indicates a continuous distribution of the species along the coast with no significant breaks in survey catches. The majority of splitnose rockfish catch occurs between 183 and $425 \mathrm{~m}$, which is consistent with previous knowledge of splitnose rockfish distribution by depth (Boehlert 1980, Love et al. 2002).

The size of fish caught within the survey ranged between 4 and $42 \mathrm{~cm}$, while ages ranged between 0 and 103 yr. Comparisons of ages by reader for each gender are given in Fig. 3. There was no apparent systematic ageing bias or high random ageing imprecision, and all ages (both single and double reads) were therefore used to estimate growth parameters and incorporate ageing error via a random effects model (Cope \& Punt 2007). Von Bertalanffy growth curves fitted to female and male splitnose rockfish size-at-age data for each biogeographic area are shown in Figs. $4 \& 5$. Growth parameters $L_{\infty}, k$, and $t_{0}$, along with their standard deviations, are also provided for each curve. Figs. 4 \& 5 demonstrate that in every biogeographic area females reach larger asymptotic sizes than males, while males reach their asymptotic size faster.

The results of the linear regression model selection evaluating 6 hypotheses regarding latitudinal variability of von Bertalanffy growth parameters $L_{\infty}$ and $k$ by gender are shown in Fig. 6. Models with the lowest AIC values are most supported by the data, and models with AIC differences $(\triangle \mathrm{AIC})$ greater than 2 are significantly undersupported by the data.

The results indicate strong support for a cline in $L_{\infty}$ for both genders, with the asymptotic length increasing as latitude increases. Conversely, the results showed no support for a cline in the growth coefficient $k$, but instead strong support for a break in $k$ at Monterey Bay (for females) and at Point Conception (for males), with both genders growing slower in the most southern areas than along the rest of the coast (Fig. 6).

\section{DISCUSSION}

\section{General findings}

Our results indicate that over the studied period, splitnose rockfish exhibited a cline in asymptotic length, with $L_{\infty}$ increasing with rising latitude. Our results also indicated the smallest growth coefficient (k) south of Monterey Bay (females) and south of the Point Conception (males) with no apparent cline along 
the rest of the coast. A northward cline along the U.S. west coast has been previously reported in the literature (Boehlert \& Kappenman 1980). Although our specific conclusions differ from those of Boehlert \& Kappenman (1980), results of the present study and theirs seem to agree, and therefore a reinterpretation of their results is warranted. Boehlert \& Kappenman (1980) found that the growth curves for the 3 areas they studied along the coast (with breaks at $37^{\circ} 07^{\prime}$ and $40^{\circ} 25^{\prime} \mathrm{N}$ ) were significantly different from one another, using a predictive sampling reuse procedure. Furthermore, they estimated von Bertalanffy growth parameters for each area. Although they reported northward clines for the splitnose rockfish in both $L_{\infty}$ and $k$, examination of their parameter estimates for $k$ reveals no cline. Their reported trend in $L_{\infty}$ on the other hand, does follow the northward cline found in the present study. Therefore, and in agreement with what we have found, the differences in growth curves observed by Boehlert \& Kappenman are attributed mostly to differences in $L_{\infty}$, with no trend in the growth coefficient $k$.

\section{Explaining latitudinal differences in growth parameters}

Over the years several hypotheses have been proposed to explain latitudinal variability in splitnose rockfish growth. One is based on the assumption that there are 2 stocks of splitnose rockfish in the waters off the U.S. west coast at the break at Cape Mendocino (Boehlert \& Kappenman 1980). Such a distinction is not supported by the comparison of growth parameters conducted in the present study. Also, although no genetic data are currently available on stock structure of the splitnose rockfish (Waples et al. 2008), we fur-

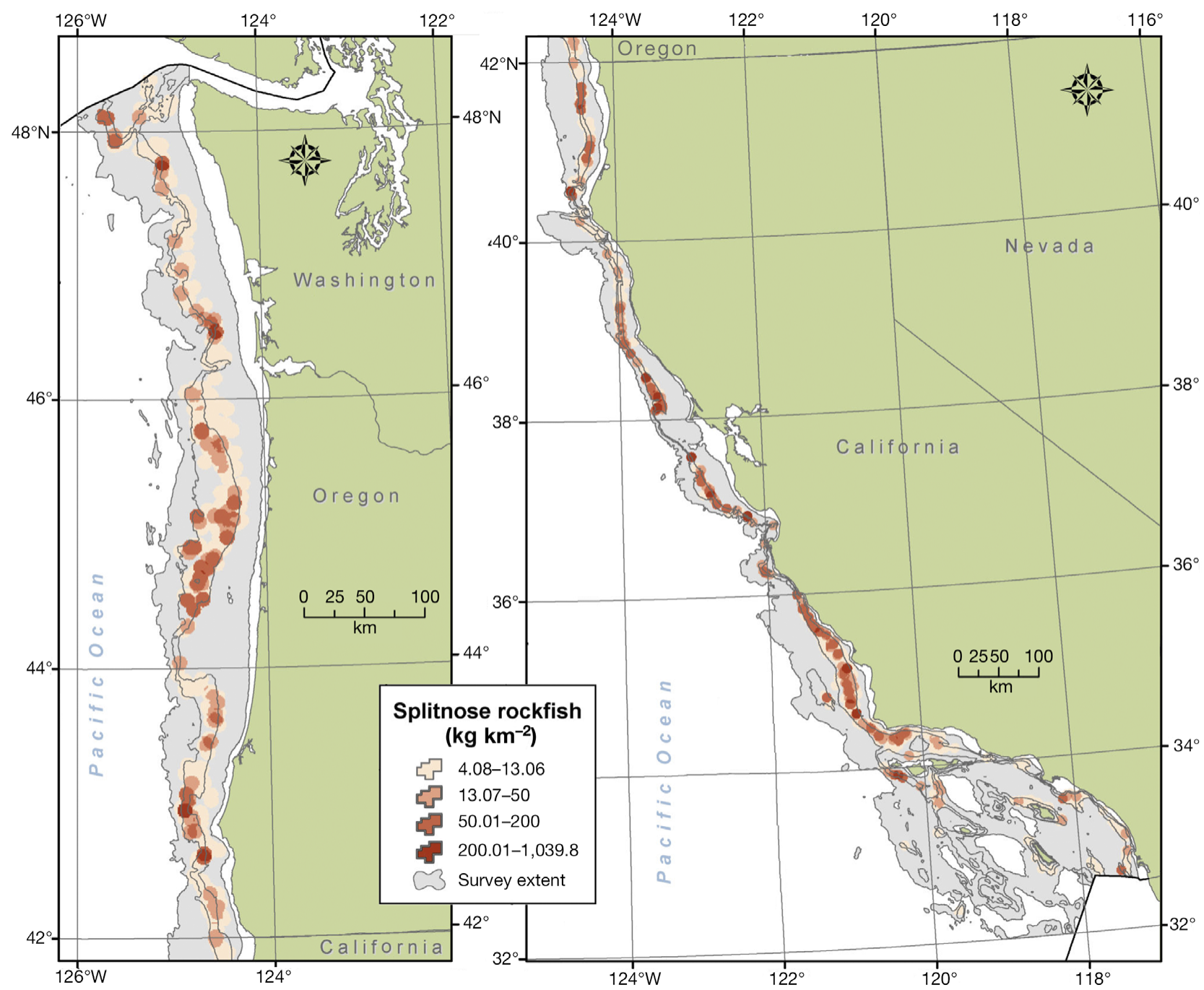

Fig. 2. Sebastes diploproa. Density of splitnose rockfish catch during the Northwest Fisheries Science Center (NWFSC) Groundfish Survey (2003-2008). Three main survey strata are defined by the 30-, 100-, 300- and 700-fathom isobaths 


\section{Females}
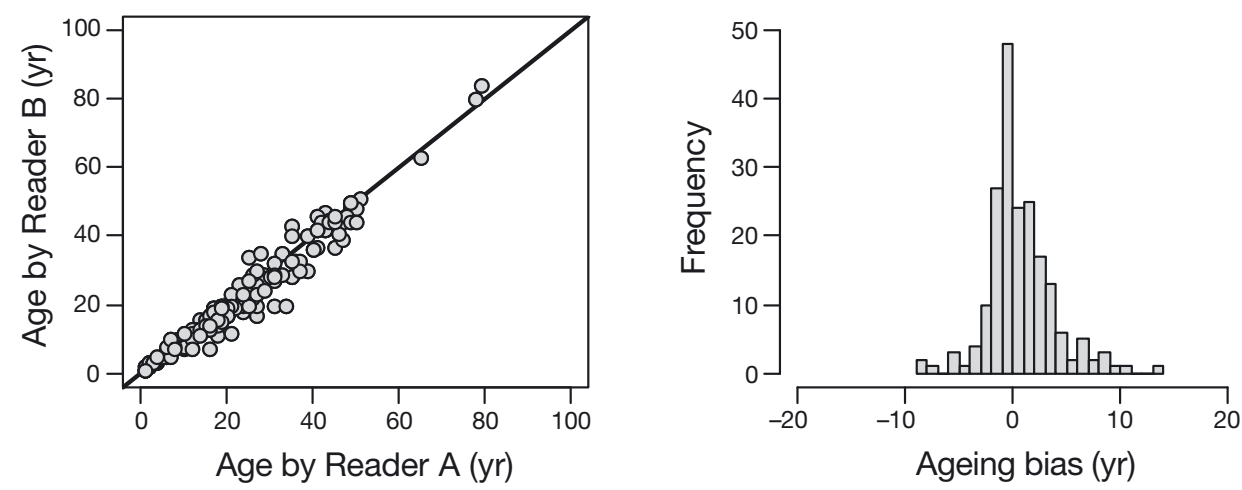

Males
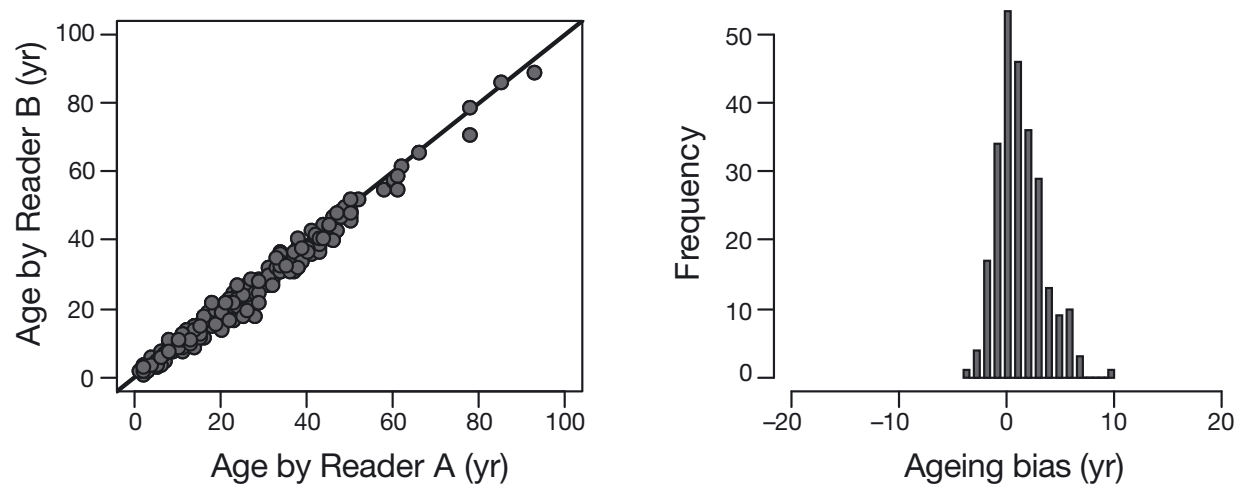

Fig. 3. Sebastes diploproa. Comparison of splitnose rockfish ages (by gender) estimated by Readers A and B. Left panels are the 1:1 plots with the black line indicating perfect agreement; right panels are histograms that show differences between ages estimated by 2 readers (Reader A- Reader B)

ther explored the hypothesis of ecological-scale population structure using the management unit estimator (MUE) method of Cope \& Punt (2009). This method uses spatially resolved time series of abundance data with associated uncertainty to identify groups of areas with similar population dynamics and thus demonstrates demographic connectivity. Gertseva et al. (2009) used abundance indices for each year of the NOAA Fisheries Groundfish Survey and uncertainty around these indices (coefficients of variation) estimated for each biogeographic area as inputs into the MUE. Using a 2-step clustering approach, the areas were assigned to management units most supported by the data, and the analysis yielded no evidence of spatial stock structure for splitnose rockfish off Washington, Oregon, and California (Gertseva et al. 2009).

Another hypothesis proposed is that intraspecific variability in splitnose rockfish growth might be caused by environmental factors, such as temperature and food availability (Beverton \& Holt 1959, Boehlert \& Kappenman, 1980), with environment affecting both growth coefficient $k$ and asymptotic length $L_{\infty}$ but not solely $L_{\infty \prime}$ which we detected most strongly in the present study. Moreover, the relationship between $L_{\infty}$ and $k$ is often assumed to be inversely proportional (Gallucci \& Quinn 1979). Beverton \& Holt (1959), for example, suggested that fish in warmer waters tend to grow faster due to increased metabolic rate (since they are poikilotherms), but reach smaller sizes than those in cooler water. In such cases, it has been proposed that differences in asymptotic length most likely result from higher natural mortality in organisms with faster growth rate, which was described for a variety of organisms (Beverton \& Holt 1959, Charnov 1993), so that fish in warmer water die before reaching the size of fish in cooler waters. Beverton \& Holt (1959) also initially suggested that food availability modifies the asymptotic length only and does not affect the parameter $k$, but they later stated that better supply of food per fish also typically results in an increased growth rate (Beverton \& Holt 1959).

The effect of food availability on fish growth has been discussed by several authors. Splitnose rockfish primarily feed on euphausiids (Phillips 1964), but also eat copepods, sergestid shrimps, and amphipods 
(Brodeur \& Pearcy 1984). Although it is extremely difficult to estimate the amount of euphausiids available over the geographic range of the splitnose rockfish, especially relative to fish trophic needs, there have been attempts to indirectly implicate food availability through density-dependent mechanisms in order to explain variability in this species growth parameters by latitude. For example, Boehlert \& Kappenman (1980) explained their findings of a growth rate cline (which our results did not support) by suggesting that in the 1960s the fishing pressure on splitnose rockfish was much higher in the northern part of the species range than in the south, due to extensive foreign and
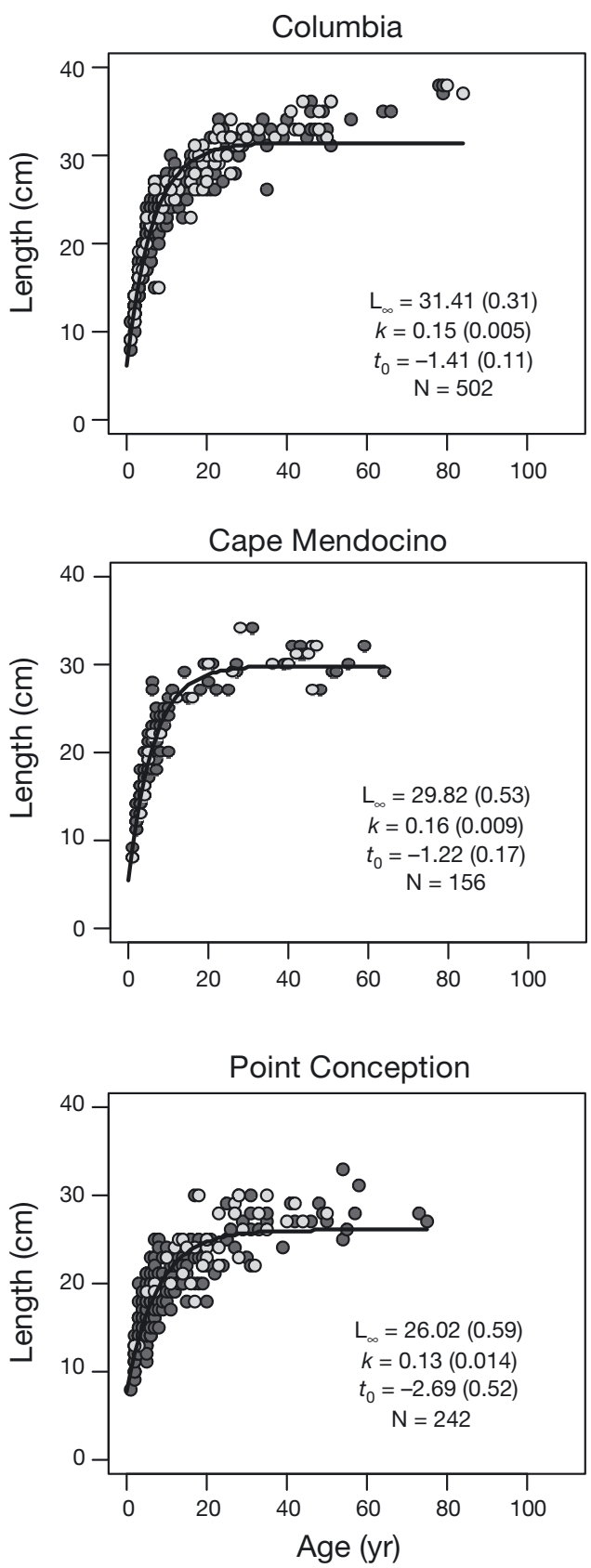

domestic fisheries targeting Pacific ocean perch, the species that co-occurs with splitnose rockfish in waters off Washington and Oregon. Even though splitnose rockfish was not targeted, a significant amount might have been removed as incidental catch (Boehlert \& Kappenman 1980). The hypothesis was based on the assumption of higher fishery removals on the north, but at the time of the study only limited and indirect information on splitnose rockfish commercial catches was available.

We addressed this hypothesis by conducting a detailed historical reconstruction of splitnose rockfish landings from all available published sources and
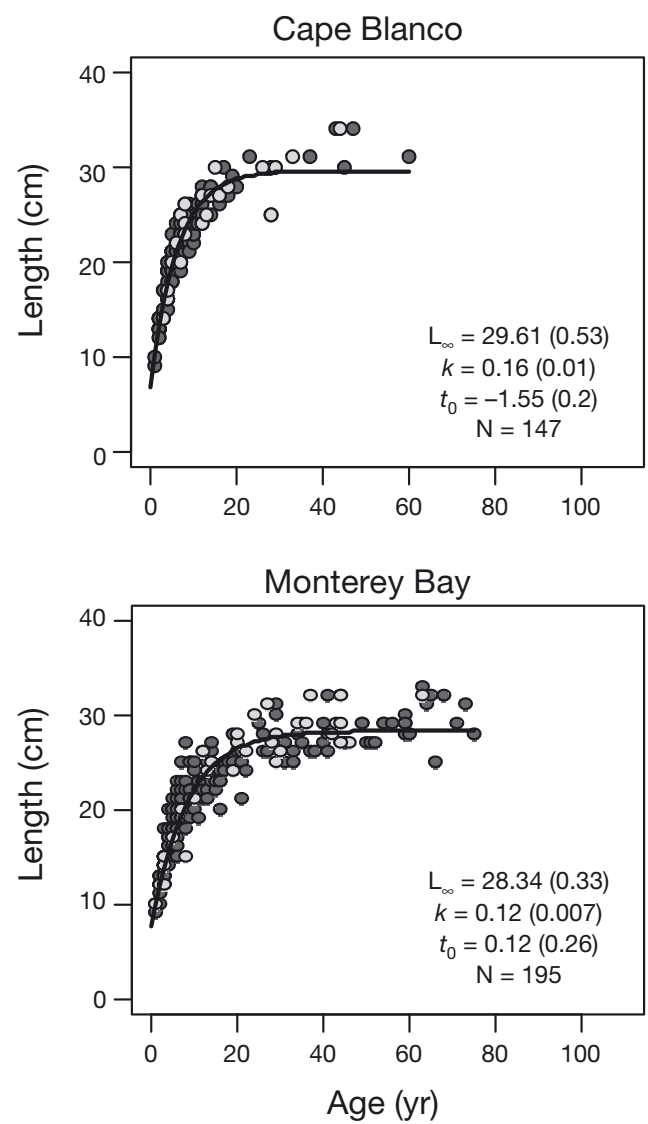

Fig. 4. Sebastes diploproa. Female splitnose rockfish length-at-age plots using data from the NWFSC Groundfish Survey (2003-2008) for each biogeographic area. Columbia: north of Cape Blanco; Cape Blanco: between Cape Blanco and Cape Mendocino; Cape Mendocino: between Cape Mendocino and Monterey Bay; Monterey Bay: between Monterey Bay and Point Conception; Point Conception: south of Point Conception. Parameter standard deviations are provided in parentheses. $\mathrm{L}_{\infty}$ : asymptotic fish length; N: number of samples 
databases, and records of catch species composition (described in detail in Gertseva et al. 2009). We found that although splitnose rockfish was often caught incidentally in the Pacific ocean perch fishery, overall the majority of splitnose rockfish was caught off California (Fig. 7). Therefore, it is unlikely that growth of splitnose rockfish would be higher in the north than in the south due to density-dependent effects caused by heavy fishery removals off Washington and Oregon. Dorn (1992) also suggested that since euphausiids are the principal prey not only for splitnose rockfish and other Sebastes species, but also support numerous fish
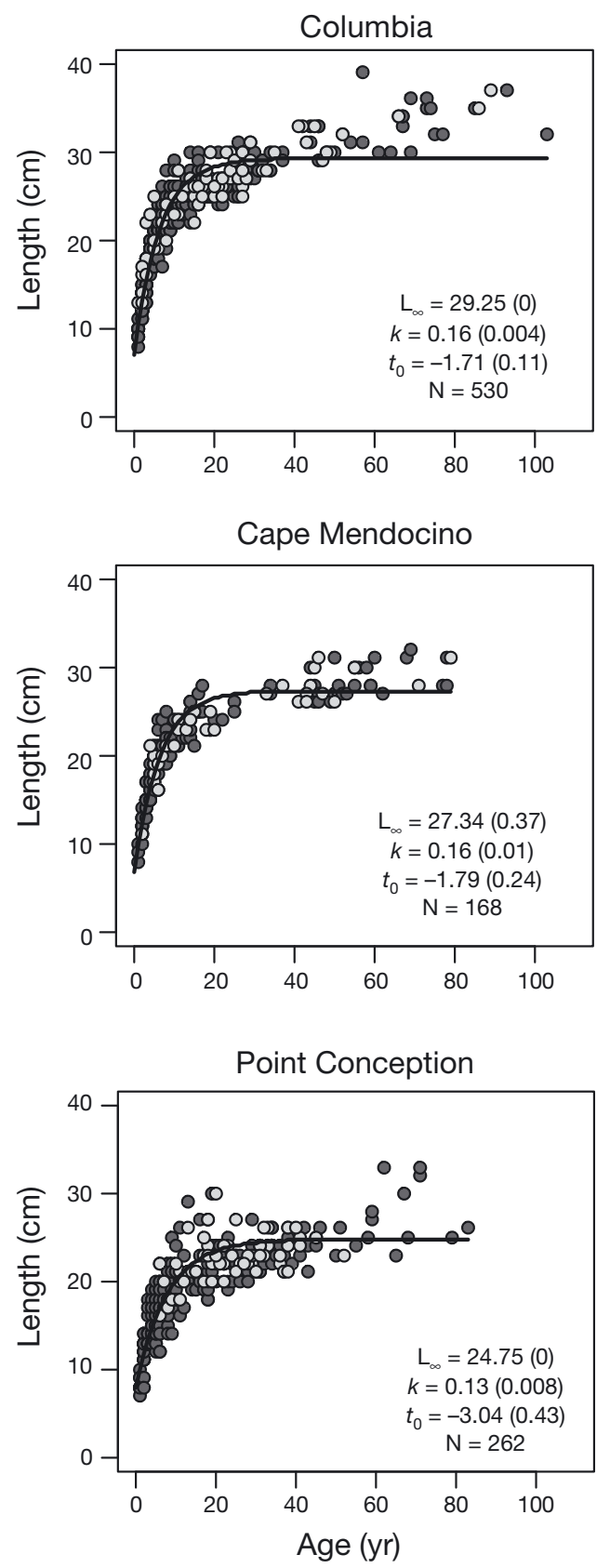

populations of the California Current System, it is unlikely that changes in the abundance of several Sebastes species alone could have had a substantial impact on the overall abundance of euphausiids.

Environmental effects on splitnose rockfish growth were studied further by Black et al. (2005) and Black (2009) using crossdating technique from dendrochronology. Crossdating is based on the assumptions that growth increment width in hard parts, like otoliths, is limited by some aspect of climate, and since the intensity of this climatic variable fluctuates over regular time intervals, climate induces covarying growth
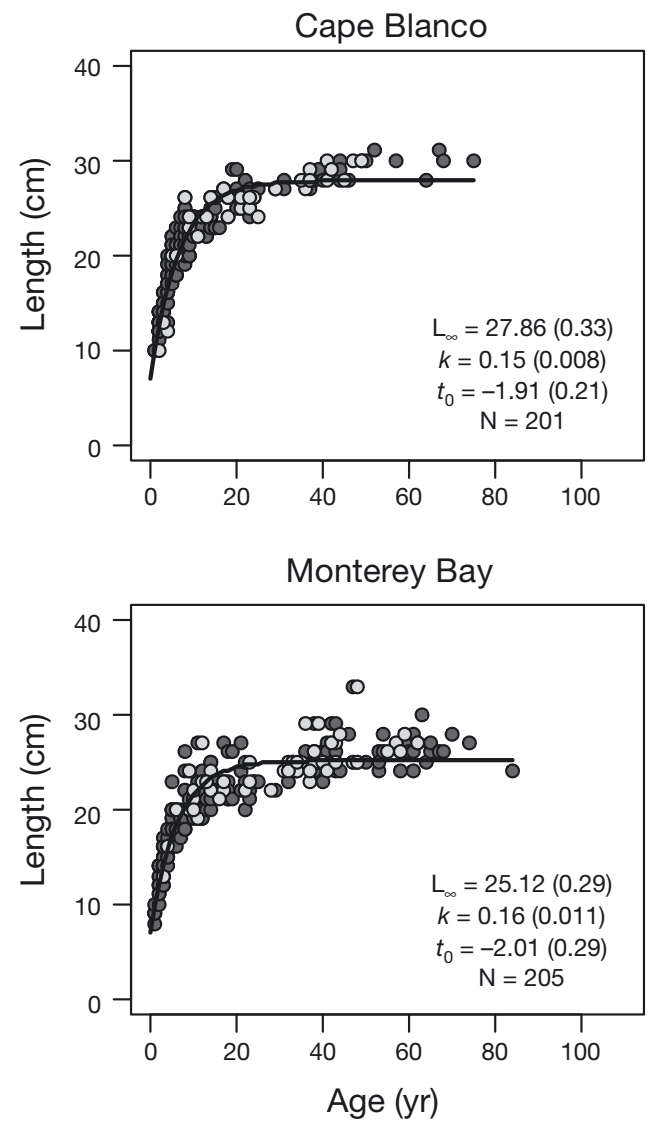

Fig. 5. Sebastes diploproa. Male splitnose rockfish length-at-age plots using data from the NWFSC Groundfish Survey (2003-2008) for each biogeographic area. See Fig. 4 for details on areas and parameters. Parameter SDs are provided in parentheses.

$\mathrm{N}$ : number of samples 
patterns in otolith increment widths much as it does in tree rings (Black et al. 2005). Black et al. (2005) studied annual growth increments formed in splitnose rockfish otoliths collected between Point Conception and Cape Mendocino (Fig. 1) to estimate fish age, and then correlated otolith growth patterns with climate records. They found that cool ocean conditions and high levels of upwelling positively affected splitnose growth, while El Niño events, warm phases of the Pacific Decadal Oscillation (PDO), and downwelling led to narrow growth increments in splitnose rockfish. As a mechanism for the observed pattern, Black et al. (2005) suggested that warm ocean conditions indicate periods of low ocean productivity and reduced growth in splitnose rockfish, while cooler ocean conditions appear to indicate periods of enhanced productivity, which leads to increased growth.

Findings of Black et al. (2005) may give clues to reasons for the smaller growth coefficient in the southern biogeographic areas than in the other biogeographic areas that we observed. Point Conception (Fig. 1) is a
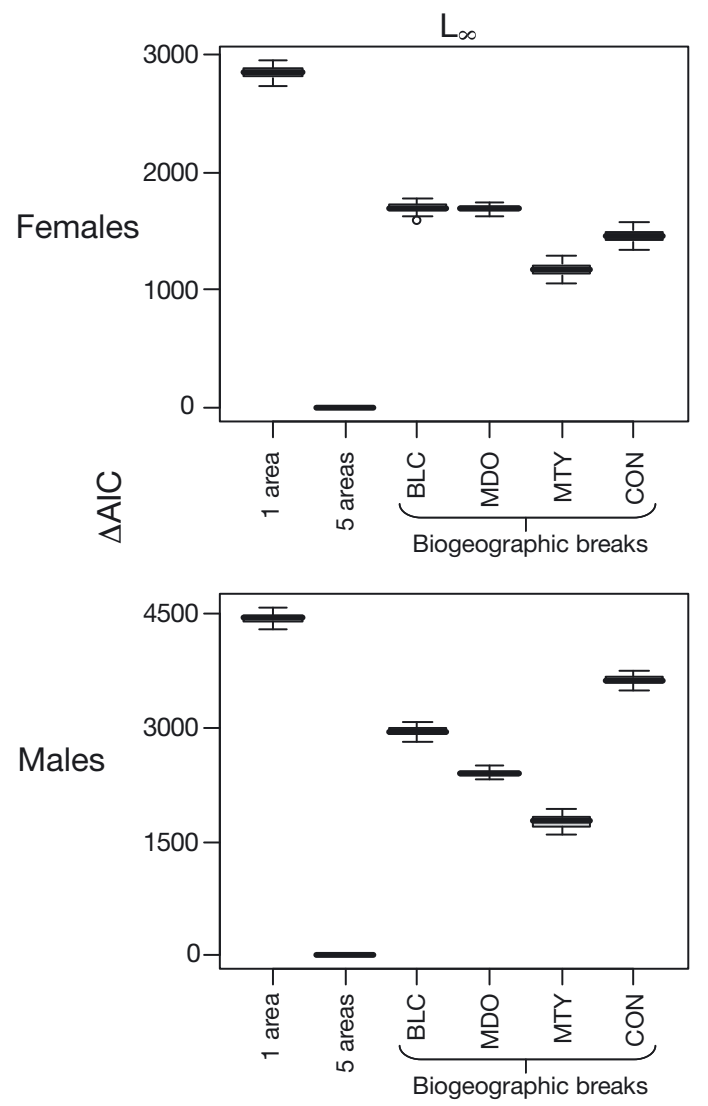

major oceanographic transition zone that divides the California coast into 2 regions with very different circulation patterns (Hickey 1998, Blanchette \& Gaines 2007). The region north of Point Conception is characterized by strong coastal upwelling that brings cold, nutrient-rich waters to the surface, and results in both cold sea surface temperatures and high nutrient concentrations along the coast (Caldwell et al. 1986, Henderschott \& Winant 1996, Blanchette \& Gaines 2007). The region south of Point Conception is, on the contrary, characterized by weak seasonal upwelling and low productivity (Hickey 1998, Ware \& Thomson 2005, Blanchette \& Gaines 2007). Given that splitnose rockfish growth was shown to be sensitive to oceanographic conditions and particularly ocean productivity (Black et al. 2005, Black 2009), fish in the more oligotrophic waters south of Point Conception would be expected to exhibit slower growth compared to those who occupy waters north of Point Conception with strong upwelling and periods of enhanced ocean productivity. Interestingly enough, for females we
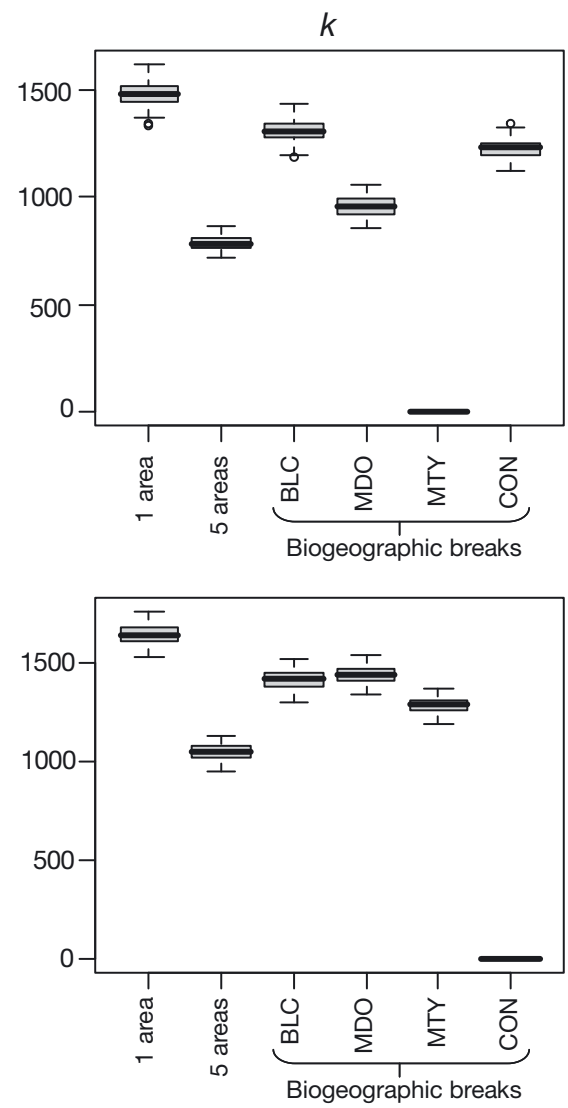

Area hypothesis

Fig. 6. Sebastes diploproa. Boxplots of $\triangle$ AIC values for 6 formulated hypotheses of the relationship of area with asymptotic length ( $L_{\infty}$ i left column) and von Bertalanffy growth parameter ( $k_{i}$ right column) for female (top row) and male (bottom row) splitnose rockfish. Hypotheses include: 1 area (no difference among areas); 5 areas (parameters in all areas are different); BLC: break at Cape Blanco; MDO: break at Cape Mendocino; MTY: break at Monterey Bay; CON: break at Point Conception. Lowest $\Delta$ AIC indicate models with greatest support. Models with $\triangle \mathrm{AIC}>2$ are significantly undersupported by the data 


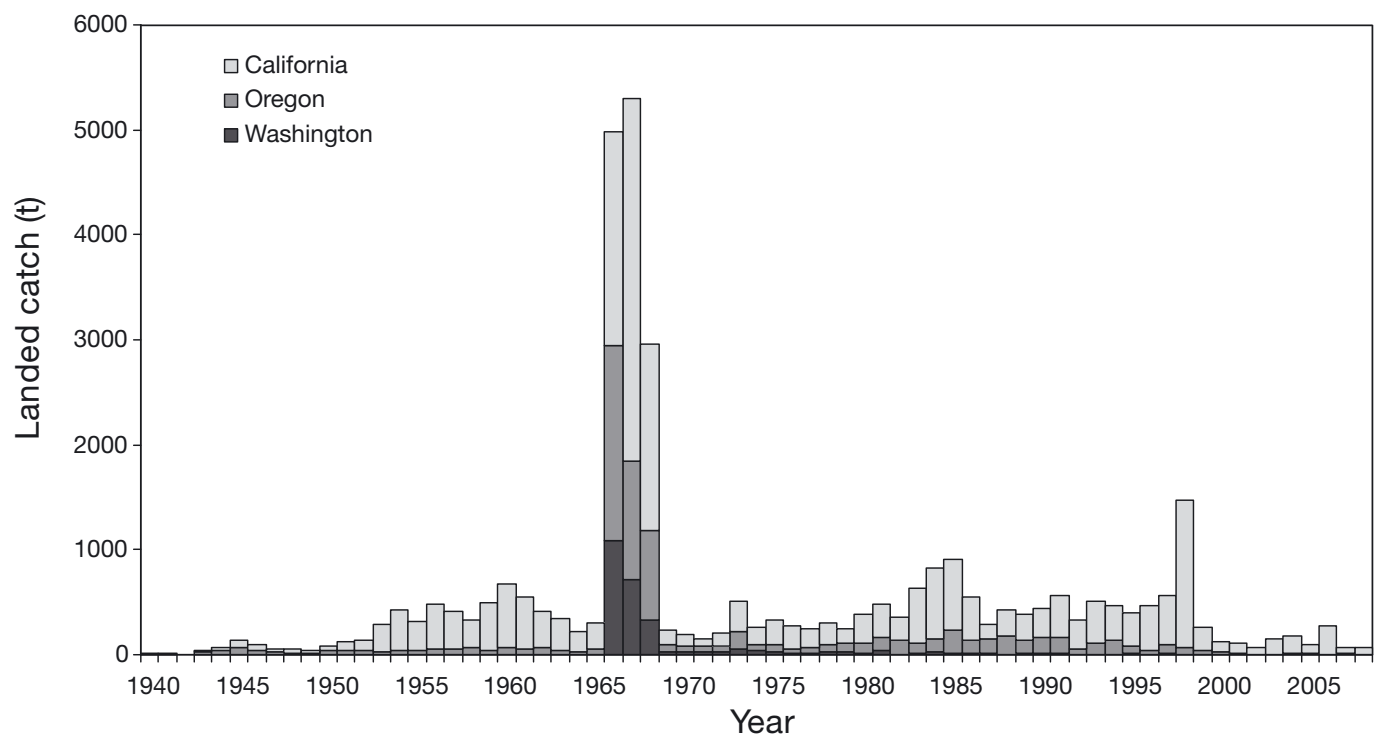

Fig. 7. Sebastes diploproa. Reconstructed historical catch (1940-2008) of splitnose rockfish landed in California, Oregon, and Washington

detected slower growth slightly north of Point Conception as well, but not for males. Although the mechanisms behind our findings are still to be determined, our results reveal the need to explore sexual dimorphism in rockfish further while studying spatial aspects of their ecology and life history.

While a slower growth rate in the Point Conception area in the present study can be attributed to the oceanographic characteristics of the coast, the cline in splitnose asymptotic length can be better understood in relation to fishery removals. The vast majority of commercial fishery removals have occurred in waters off California (Fig. 7). At the same time, Fig. 2 shows that the density of survey catches, although somewhat higher off California, does not grossly differ along the coast. Differences in selectivity may cause differential size class removal, so we considered the size composition of both landed and discarded fish. Although limited size composition data from landed catches in Washington and Oregon and of discarded fish were collected, the available data were adequate to conclude that size frequencies of landed and discarded fish do not vary significantly by state, and that size frequencies of catch do not change with latitude (Gertseva et al. 2009). This indicates no evidence of differences in fishery size selectivity, when the southern fishery would select larger fish than fishery in the north. However, even though equal in size selectivity, much higher fishing pressure in the south could skew the size distribution of the population in that region and reduce southern $L_{\infty}$ survey estimates simply by removing more large fish (fisheries traditionally focus on larger individuals) relative to the abundance in the south than in the north, thus producing a latitudinal cline in $L_{\infty}$.
To support the hypothesis of fishery removals, we present the ratio of landed catch to the relative abundance of splitnose rockfish among west coast states for the most recent $5 \mathrm{yr}$, when survey abundance data were available (Fig. 8). This ratio is a measure of fishing intensity relative to population abundance; the higher the ratio, the higher the fishing pressure in the area. We found that even though the estimated abundance of splitnose rockfish was higher off California during the survey years, the fishing pressure was also much higher there. These results did not change when we increased the landed catch by the available discard estimates from the West Coast Groundfish Observer program. We do not infer from Fig. 8 that removals during the last 5 yr have specifically affected the latitudinal pattern in $L_{\infty}$ they are used to illustrate that fishing intensity is not uniformly distributed along the

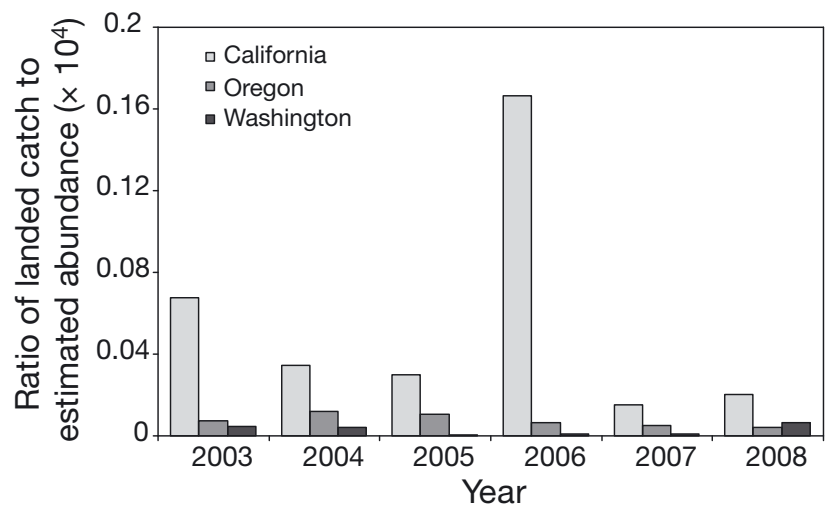

Fig. 8. Sebastes diploproa. Comparison of ratio of landed catch to estimated abundance of splitnose rockfish for California, Oregon, and Washington 
coast and that fish are taken disproportionally to their abundance, thus more of the larger individuals would be removed in areas with higher fishing intensity. Interestingly enough, Fig. 8 indicates that fishing pressure on the west coast over the last 5 yr changes gradually (decreasing from California to Washington), and is inversely correlated with our estimates of $L_{\infty}$.

In conclusion, the present study offers updated insight into the differences in growth parameters in a marine fish across a wide latitudinal span. We included several important improvements such as data quality (the use of sectioned otoliths with double reads), as well as improvements in model fitting (e.g. the incorporation of ageing error in fitting the growth curve) and the analysis of the latitudinal variability in splitnose rockfish growth parameter estimates. Our results indicate that a combination of oceanographic characteristics and extended periods of fishery removals may produce distinct growth differences within species that lack any detectable population structure. Such systematic differences in intraspecific growth among areas should be explored further to elucidate whether these patterns are consistent across species, and thus represent expected patterns of spatial biological differentiation (Cope 2006), or are only a special case in a system of more widely homogenous growth patterns.

Acknowledgements. We thank the entire survey team of the NWFSC Fisheries Analysis and Monitoring Division (FRAMD) and Newport Ageing Laboratory for collecting and processing survey data, but particularly Beth Horness, who always quickly responded to our data requests, Curt Whitmire for generating maps for this paper, and Patrick McDonald and Betty Kamikawa for ageing splitnose rockfish. We also thank Drs. Waldo Wakefield, Richard Brodeur, and Thomas Wainwright of NWFSC for their comments on the manuscript.

\section{LITERATURE CITED}

Alverson DL, Pruter AT, Ronholt LL (1964) A study of the demersal fishes and fisheries of the northeastern Pacific Ocean. In: MacMillan HR (ed) Lectures in fisheries. Institute of Fisheries, University of British Columbia, Vancouver

Beamish RJ, Fournier DA (1981) A method for comparing the precision of a set of age determinants. Can J Fish Aquat Sci 38:982-983

Begg GA (2005) Life history parameters. In: Cardin SX, Friedland KD, Waldman JR (eds) Stock identification methods application in fishery science. Elsevier Academic Press, Amsterdam, p 119-172

Begg GA, Waldman JR (1999) An holistic approach to fish stock identification. Fish Res 43:35-44

Bennett JT, Boehlert GW, Turekian KK (1982) Confirmation of longevity in Sebastes diploproa (Pisces: Scorpaenidae) from ${ }^{210} \mathrm{~Pb} /{ }^{226} \mathrm{Ra}$ measurements in otoliths. Mar Biol 71: 209-215

Beverton RJH, Holt SJ (1959) A review of the lifespan and mortality rates of fish in nature, and the relation to growth and other physiological characteristics. In: Wolstenholme
GEW, O'Connor M (eds) CIBA Foundation Colloquia on ageing, Vol 5. The lifespan of animals. Little, Brown and Co, Boston, MA, p 144-177

> Black BA (2009) Climate-driven synchrony across tree, bivalve, and rockfish growth-increment chronologies of the northeast Pacific. Mar Ecol Prog Ser 378:37-46

> Black BA, Boehlert GW, Yoklavich MM (2005) Using tree-ring cross-dating techniques to validate annual growth increments in long-lived fishes. Can J Fish Aquat Sci 62: $2277-2284$

> Blanchette CA, Gaines SD (2007) Distribution, abundance, size and recruitment of the mussel, Mytilus californianus, across a major oceanographic and biogeographic boundary at Point Conception, California, USA. J Exp Mar Biol Ecol 340:268-279

Boehlert GW (1977) Timing of the surface-to-benthic migration in juvenile rockfish, Sebastes diploproa, off southern California. Fish Bull 75:887-890

Boehlert GW (1978) Changes in the oxygen consumption of prejuvenile rockfish, Sebastes diploproa, prior to migration from the surface to deep water. Physiol Zool 51:56-67

Boehlert GW (1980) Size composition, age composition, and growth of canary rockfish, Sebastes pinniger, and splitnose rockfish, $S$. diploproa, from the 1977 rockfish survey. Mar Fish Rev 42:57-63

Boehlert GW (1985) Using objective criteria and multiple regression models for age determination in fishes. Fish Bull 82:103-117

Boehlert GW, Kappenman RF (1980) Variation of growth with latitude in two species of rockfish (Sebastes pinniger and S. diploproa) from the Northeast Pacific Ocean. Mar Ecol Prog Ser 3:1-10

Boehlert GW, Yoklavich MM (1984) Variability in age estimates in Sebastes as a function of methodology, different readers, and different laboratories. Calif Fish Game 70: 210-224

Brodeur RD, Pearcy WG (1984) Food habits and dietary overlap of some shelf rockfishes (genus Sebastes) from Northeastern Pacific Ocean. Fish Bull 82:269-293

Broitman BR, Blanchette CA, Menge BA, Lubchenco J and others (2008) Spatial and temporal patterns in invertebrate recruitment along the west coast of the United States. Ecol Monogr 78:403-421

Burnham KP, Anderson DR (2002) Model selection and multimodel inference: a practical information-theoretic approach, 2nd edn. Springer, New York, NY

Burton RS (1998) Intraspecific phylogeography across the Point Conception biogeographic boundary. Evolution 52: 734-745

Caldwell PC, Stuart DW, Brink KH (1986) Mesoscale wind variability near Point Conception, California during spring 1983. J Clim Appl Meteorol 25:1241-1254

Campana SE (2001) Accuracy, precision and quality control in age determination, including a review of the use and abuse of age validation methods. J Fish Biol 59:197-242

Chang WYB (1982) A statistical method for evaluating the reproducibility of age determination. Can J Fish Aquat Sci 39:1208-1210

Charnov EL (1993) Life history invariants some explorations of symmetry in evolutionary ecology. Oxford University Press, New York, NY

Cope JM (2004) Population genetics and phylogeography of the blue rockfish (Sebastes mystinus) from Washington to California. Can J Fish Aquat Sci 61:332-342

Cope JM (2006) Exploring intraspecific life history patterns in sharks. Fish Bull 104:311-320

Cope JM, Punt AE (2007) Admitting ageing error when fitting 
growth curves: an example using the von Bertalanffy growth function with random effects. Can J Fish Aquat Sci 64:205-218

Cope JM, Punt AE (2009) Drawing the lines: resolving fishery management units with simple fisheries data. Can J Fish Aquat Sci 66:1256-1273

Dorn MW (1992) Detecting environmental covariates of Pacific whiting Merluccius productus growth using a growth-increment regression model. Fish Bull 90:260-275

Gallucci VF, Quinn TJ (1979) Reparameterizing, fitting, and testing a simple growth model. Trans Am Fish Soc 108: $14-25$

Gertseva VV, Cope JM, Pearson DE (2009) Status of the U.S. splitnose rockfish (Sebastes diploproa) resource in 2009. In: Status of the Pacific Coast Groundfish Fishery through 2009 and recommended acceptable biological catches for 2011/2012: stock assessment and fishery evaluation, 2009. Pacific Fishery Management Council, Portland, OR, p 1-272

Gunderson DR, Sample TM (1980) Distribution and abundance of rockfish off Washington, Oregon, and California during 1977. Mar Fish Rev 42:2-16

Haddon M (2001) Modeling and quantitative methods in fisheries. Chapman and Hall/CRC, Boca Raton, FL

Hamel OS (2005) Status and future prospects for the Pacific ocean perch resource in waters off Washington and Oregon as assessed in 2005. In: Status of the Pacific Coast Groundfish Fishery through 2005: stock assessment and fishery evaluation. Pacific Fishery Management Council, Portland, OR, p 1-76

Henderschott MC, Winant CD (1996) Surface circulation in the Santa Barbara channel. Oceanography 9: 114-121

Hickey BM (1998) Coastal oceanography of western North America from the tip of Baja to Vancouver Island. In: Robinson AR, Brink KH (eds) The sea, the global coastal ocean: regional studies and syntheses, Vol 11. Wiley, New York, NY, p 345-393

Hilborn R, Mangel M (1997) The ecological detective: confronting models with data. Princeton University Press, Princeton, NJ

Hilborn R, Walters CJ (2001) Quantitative fisheries stock assessment choice, dynamics and uncertainty. Kluwer Academic Press, Boston, MA

Hobbs NT, Hilborn R (2006) Alternatives to statistical hypothesis testing in ecology: a guide to self teaching. Ecol Appl 16:5-19

Hoenig JM (1983) Empirical use of longevity data to estimate mortality rates. Fish Bull 82:898-902

Hyde JR, Vetter RD (2009) Population genetic structure in the redefined vermilion rockfish (Sebastes miniatus) indicates limited larval dispersal and reveals natural management units. Can J Fish Aquat Sci 66:1569-1581

Ihssen PE, Booke HE, Casselman J, McGlade JM, Payne NR, Utter FM (1981) Stock identification: materials and methods. Can J Fish Aquat Sci 38:1838-1855

Johansson ML, Banks MA, Glunt KD, Hassel-Finnegan HM, Buonaccorsi VP (2008) Influence of habitat discontinuity, geographical distance, and oceanography on fine scale population genetic structure of copper rockfish (Sebastes

Editorial responsibility: Nicholas Tolimieri, Seattle, Washington, USA caurinus). Mol Ecol 17:3051-3061

Keller AA, Horness BH, Simon VH, Tuttle VJ and others (2007) The US West Coast trawl survey of groundfish resources off Washington, Oregon, and California: estimates of distribution, abundance, and length composition in 2004. NOAA Tech Memo NMFS-NWFSC, U.S. Department of Commerce

Lai HL, Gallucci VF, Gunderson DR (1995) Age determination in fisheries: methods and applications to stock assessment. In: Gallucci VF, Saila SB Gustafson D, Rothschild R (eds) Stock assessment: quantitative methods and applications for small scale fisheries. CRC Press, Boca Raton, FL, p 82-178

Love MS, Yoklavich M, Thorsteinson L (2002) The rockfishes of the northeast Pacific. University of California Press, Berkeley

Parrish RH, Nelson CS, Bakun A (1981) Transport mechanisms and reproductive success of fishes in the California Current. Biol Oceanogr 1:175-203

Phillips JB (1964) Life history studies on ten species of rockfish (Genus Sebastodes). Fish Bull Calif Dep Fish Game 126: $1-64$

Quinn TJ, Desiro RB (1999) Quantitative fish dynamics. Oxford University Press, New York, NY

R Development Core Team (2010) R: a language and environment for statistical computing. R Foundation for Statistical Computing, Vienna

Rogers JB (1994) Preliminary status of the splitnose rockfish in 1994. In: The status of the Pacific Coast Groundfish through 1994 and recommended acceptable biological catches for 1995. Pacific Fishery Management Council, Portland, OR, Apendix $\mathrm{H}$

Rogers JB (2005) Status of the darkblotched rockfish (Sebastes crameri) resource in 2005. In: Status of the Pacific Coast groundfish fishery through 2005: stock assessment and fishery evaluation. Pacific Fishery Management Council, Portland, OR, p 1-133

Rogers JB, Pikitch EK (1992) Numerical definition of groundfish assemblages caught off the coast of Oregon and Washington using commercial fishing strategies. Can J Fish Aquat Sci 49:2648-2656

Sivasundar A, Palumbi SR (2010) Life history, ecology and the biogeography of strong genetic breaks among 15 species of Pacific rockfish, Sebastes. Mar Biol 157:1433-1452

Tagart JV, Kimura DK (1982) Review of Washington's coastal trawl rockfish fishery. Tech Rep 68, Washington Department of Fishery, Olympia, WA

von Bertalanffy L (1938) A quantitative theory of organic growth (inquiries on growth laws II). Hum Biol 10:181-213

Waples RS, Punt AE, Cope JM (2008) Integrating genetic data into management of marine resources: How can we do it better? Fish Fish 9:423-449

Ware DM, Thomson RE (2005) Bottom-up ecosystem trophic dynamics determine fish production in the northeast Pacific. Science 308:1280-1284

Williams EH, Ralston S (2002) Distribution and co-occurrence of rockfishes (family: Sebastidae) over trawlable shelf and slope habitats of California and southern Oregon. Fish Bull 100:836-855

Submitted: February 9, 2010; Accepted: June 28, 2010

Proofs received from author(s): August 18, 2010 